\title{
PERENCANAAN EKSTERIOR MAJELIS TAKLIM AL MUSA'ADAH, PARUNG PANJANG, BOGOR BERDASARKAN KONSEP ARSITEKTUR ISLAM
}

\author{
Yunita Ardianti Sabtalistia ${ }^{1}$ dan Sintia Dewi Wulanningrum ${ }^{2}$ \\ ${ }^{1}$ Jurusan Arsitektur dan Perencanaan, Universitas Tarumanagara \\ Surel: yunitas@ft.untar.ac.id \\ 2 Jurusan Arsitektur dan Perencanaan, Universitas Tarumanagara \\ Surel: sintiaw@ft.untar.ac.id
}

\begin{abstract}
Majelis Taklim Al Musa'adah is located in Parung Panjang, Bogor, West Java. The front view of the majelis taklim building is almost the same as the residence and there is no Majelis Taklim sign in front of the building. Considering the function of majelis taklim as a place for teaching and learning Islam, the Majelis Taklim should have the concept of Islamic architecture on it's exterior. Based on these problems, the purpose of this PKM is to plan the exterior of Majelis Taklim Al Musa'adah with the concept of Islamic architecture. The initial stage in this activity is collecting secondary data (literature review) and primary data (measurement data and interviews with partners). Discussions with partners (Management of the Majelis Taklim) and the Head of RT 04 Kabasiran village need to be carried out in order to reach a design agreement that is in accordance with the partners' needs and conditions in the field. The concept of Islam is seen in the dome model and the krawangan pattern. The krawangan hole in the entrance area is made of a dome model and the krawangan pattern is made hexagonal. The hexagonal was chosen because this shape has many features. In Islam, bees and honey are implied in the verses of the Al-Qur'an. In addition, leaf tendrils are used for 3D krawangan side of the building. It is hoped that the exterior planning design can be used as a design reference for the next PKM activity.
\end{abstract}

Keywords: Exterior, Islamic Architecture, Majelis Taklim, Planning

\begin{abstract}
ABSTRAK
Majelis Taklim Musa'adah berlokasi di Parung Panjang, Bogor, Jawa Barat. adalah salah satu majelis taklim di Parung Panjang yang dikhususkan untuk perempuan dan anak-anak. Tampilan depan bangunan majelis taklim ini hampir sama dengan rumah tinggal dan tidak ada papan nama Majelis Taklim di depan bangunannya. Mengingat fungsi majelis taklim sebagai tempat belajar-mengajar agama Islam maka seyogyanya Majelis Taklim ini mempunyai konsep Arsitektur Islam pada tampilan luarnya (eksterior). Berdasarkan permasalahan tersebut maka tujuan PKM ini adalah membuat perencanaan eksterior Majelis Taklim Al Musa'adah dengan konsep Arsitektur Islam. Tahapan awal dalam kegiatan ini adalah mengumpulkan data sekunder (kajian literatur) dan data primer (data pengukuran dan wawancara dengan mitra). diskusi dengan mitra (pengurus majelis Taklim) dan Ketua RT 04 desa Kabasiran perlu dilakukan agar mencapai kesepakatan desain yang sesuai dengan kebutuhan mitra dan kondisi di lapangan. Konsep islam terlihat pada model kubah dan pola krawangan. Lubang krawangan di daerah entrance dibuat model kubah dan pola krawangan dibuat heksagonal. Heksagonal dipilih karena bentuk tersebut mempunyai banyak keistimewaan. Di dalam islam, lebah dan madu tersirat di dalam ayat Al-Qur'an. Selain itu motif sulur daun digunakan untuk krawangan 3D sisi samping bangunan. Hasil desain perencanaan eksterior diharapkan dapat dijadikan acuan desain untuk tahap pelaksanaan kegiatan PKM berikutnya.
\end{abstract}

Kata kunci: Arsitektur Islam, Eksterior, Majelis Taklim, Perencanaan

\section{PENDAHULUAN}

Majelis Taklim Al Musa'adah berada di Jl. Raya Dago, RT 04, RW 01, Desa Kabasiran, Kecamatan Parung Panjang, Kabupaten Bogor, Jawa Barat. Majelis taklim ini berada di kawasan perkampungan yang berdekatan dengan Perumahan Forest Hill, Peternakan Ayam Cibadak Indah SariFarm, kawasan kota mandiri Millenium City, dan Perumahan Griya Parung Panjang. 
Majelis taklim berasal dari 2 suku kata Bahasa Arab yaitu Majelis berarti tempat dan ta'lim berarti mengajar. Jadi secara Bahasa majelis taklim mempunyai makna tempat belajar-mengajar (Jadidah, 2016:27). Adapun definisi majelis taklim secara istilah adalah sebuah lembaga pendidikan non formal yang dipandu oleh ustadz/ustadzah yang mempunyai jama'ah dalam rangka mempelajari agama Islam serta kegiatan yang bermanfaat lainnya (Jadidah, 2016:27). Fungsi majelis taklim adalah sebagai tempat kegiatan belajar-mengajar agama islam dan kegiatan positif lainnya. Menurut Mustofah, 2016:3 majelis taklim mempunyai berbagai fungsi antara lain:

1. Sebagai lembaga pendidikan non formal Islam berupa pengajian

2. Sebagai majelis pemakmuran rumah ibadah

3. Sebagai majelis pembinaan aqidah, ibadah, dan akhlak

4. Sebagai tempat peningkatan wawasan perjuangan Islam

5. Sebagai organisasi untuk meningkatkan pengelolaan amaliah berupazakat, infaq, dan shadaqah.

Majelis taklim mempunyai banyak manfaat bagi umat muslim. Adapun sejumlah manfaat Majelis Taklim adalah (Mujahidin 2018:11):

1. Menambah ilmu pengetahuan khususnya di bidang agama islam

2. Mendorong meningkatkan amal ibadah

3. Membantu dalam upaya pembinaan keluarga dan generasi muda

4. Mempererat silaturahmi antar sesama muslim

5. Memberikan ketentraman dan ketenangan batin

6. Dapat dijadikan sebagai lembaga nonformal.

Dalam konsep ajaran islam, arsitektur merupakan karya seni yang tidak lepas dari keindahan yang merujuk pada kebesaran Allah sebagai Sang Maha Pencipta (Fikriarini, 2010:196). Kita sebagai manusia hanyalah hamba yang kecil dan tidak berarti apa-apa dibandingkan dengan kebesaran Allah. Berdasarkan pemahaman tersebut maka banyak masjid didirikan dengan konsep megah dan mewah untuk menunjukkan kebesaran Allah.

Arsitektur islam merupakan wujud perpaduan antara kebudayaan manusia dan proses penghambaan diri seorang manusia kepada Tuhannya yang berada dalam keselarasan hubungan antara manusia, lingkungan, dan Penciptanya (Fikriarini, 2010:196). Arsitektur islam mengungkapkan hubungan geometris yang kompleks, hirarki bentuk, dan ornamen, serta makna simbolis yang sangat dalam (Fikriarini, 2010:196).

Arsitektur islam adalah cara membangun yang islami sebagaimana ditentukan oleh hukum syariah, tanpa batasan terhadap tempat dan fungsi bangunan tetapi lebih kepada karakter islaminya yang berhubungan dengan desain bentuk dan dekorasi (Fikriarini, 2010:197). Jadi tidak hanya bangunan monumen atau bangunan religius tapi meliputi semua jenis bangunan.

Dalam membuat desain bangunan yang berfungsi untuk kegiatan islami setidaknya mengacu pada kaidah arsitektur islam. Adapun kaidah arsitektur islam ada 8 persyaratan, yaitu (https://id.wikipedia.org/wiki/Arsitektur_Islam):

1. Di dalam dan luar bangunan tidak boleh ada gambar/ornamen makhluk hidup yang utuh

2. Di dalam dan luar bangunan terdapat ornamen yang mengingatkan kita kepada yang Maha Indah, Allah SWT

3. Hasil desain tidak ditujukan untuk pamer/kesombongan

4. Pengaturan ruang-ruang ditujukan untuk mendukung penjagaan akhlak dan perilaku

5. Posisi toilet tidak boleh menghadap atau membelakangi kiblat

6. Keberadaan bangunan tidak merugikan tetangga sekitar 
7. Pembangunan sampai berdirinya bangunan seminimal mungkin tidak merusak alam

8. Menggunakan warna yang mendekatkan kepada Allah, seperti: warna-warna alam.

Bangunan islami tidaklah harus mengikuti gaya Arsitektur Timur Tengah agar tidak menimbulkan kemubaziran karena perancangan yang tidak efesien dan belum tentu sesuai dengan kondisi wilayah nusantara (Irawan dkk,2019:301). Salah satu bangunan islami yang tidak mengikuti gaya Arsitektur Timur Tengah adalah Islamic Center di Brebes, Jawa Tengah. Adapun konsep aristektur yang digunakan bangunan tersebut adalah (Irawan dkk, 2019:301):

1. Pengingatan kepada Tuhan

2. Pengingatan kepada ibadah dan perjuangan

3. Pengingatan akan kerendahan hati

4. Pengingatan terhadap toleransi kultural

5. Pengingatan akan kehidupan berkelanjutan

6. Pengingatan tentang keterbukaan.

Majelis taklim Al Musa'adah mempunyai luas total area dalam sebesar 59,92 $\mathrm{m}^{2}$ dengan ukuran panjang 8,64 meter dan lebar 6,935 meter. Eksterior bangunan Majelis Taklim Al Musa'adah yang bercat hijau ini hampir sama dengan tampilan rumah tinggal biasa saja (Gambar 1). Bahkan tidak ada papan nama yang menunjukkan fungsi bangunan ini. Padahal posisi majelis taklim cukup strategis karena berada di pinggir jalan Raya Dago yang banyak dilalui kendaraan baik besar maupun kecil. Oleh karena itu tujuan dari PKM ini adalah membuat perencanaan desain Majelis taklim berdasarkan konsep abtraksi islami.

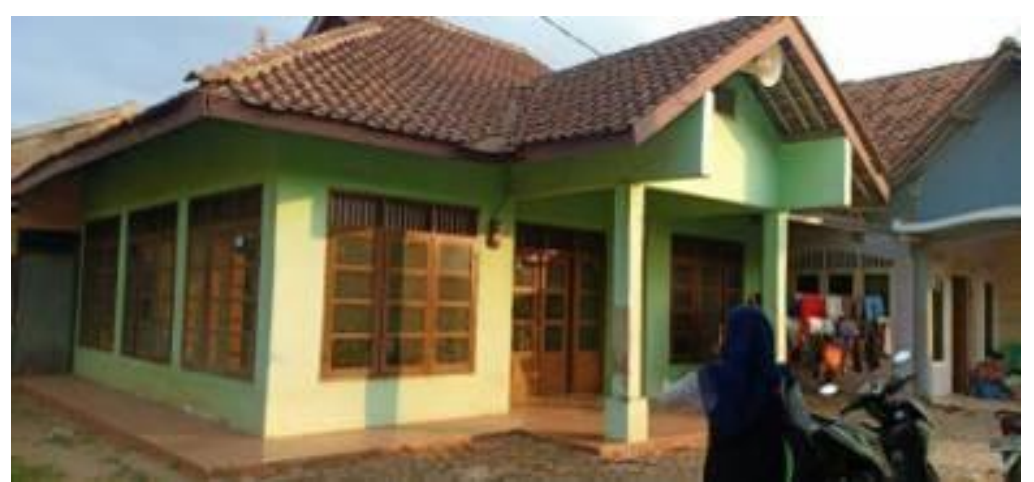

Gambar 1. Tampilan Depan (Eksterior) Majelis Taklim Al Musa'adah Sumber: Dokumentasi, Juli 2019

\section{METODE PELAKSANAAN}

Kegiatan PKM ini bertujuan untuk membuat desain perencanaan Majelis Taklim Al Musa'adah dengan konsep Arsitektur Islam. Adapun tahapan pelaksanaan kegiatan PKM ini adalah sebagai berikut:

1. Pengumpulan data sekunder

Kajian literatur tentang definisi majelis taklim, fungsi majelis taklim, dan ciri khas arsitektur islam dari jurnal-jurnal dan internet

2. Pengumpulan data primer

Pengukuran lokasi majelis taklim dan pengumpulan foto-foto kondisi eksisting untuk mengetahui permasalahan mitra. Diskusi dan wawancara dengan ketua RT 04 Desa Kebasari 
(Pak Patudin) dan Ibu Haji Masuki, Pengurus Majelis Taklim juga dilakukan untuk mengetahui lebih jelas permasalahan yang ada

3. Koordinasi tim PKM dengan Mitra (Sebelum Perencanaan)

Setelah melakukan pengumpulan data primer dan sekunder selanjutnya koordinasi tim PKM perlu dilakukan untuk membahas tentang konsep dasar bangunan untuk menghasilkan berbagai alternatif desain

4. Perencanaan Eksterior Majelis Taklim

Gambar yang dihasilkan meliputi gambar denah, tampak depan, tampak samping, potongan A-A, dan perspektif 3 dimensi (Gambar 2)

5. Koordinasi tim PKM dengan Mitra (Setelah Perencanaan)

Gambar yang dihasilkan perlu dikoordinasikan dengan mitra (Ketua RT 04 Desa Kabasiran dan pengurus Majelis Taklim) agar mendapatkan kesepakatan desain yang sesuai dengan kebutuhan mitra.

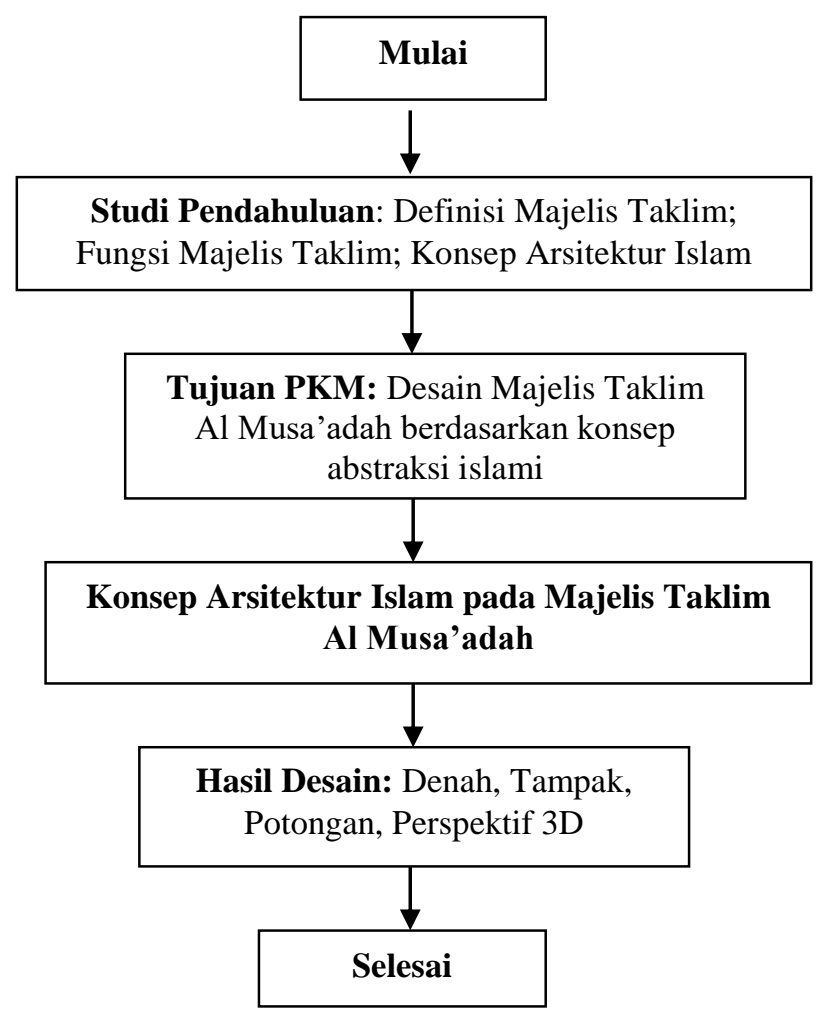

Gambar 2. Tahapan Perencanaan

\section{HASIL DAN PEMBAHASAN}

\subsection{KONDISI EKSISTING}

Bangunan sekitar majelis taklim adalah permukiman dan pertokoan. Posisi majelis taklim sangat strategis karena berada di pinggir jalan raya Dago (Gambar 3). Bangunan majelis mempunyai orientasi arah timur laut pada sisi sampingnya dan barat laut pada sisi depannya sehingga pada saat pagi dan sore cenderung sangat panas pada bagian selasarnya. 

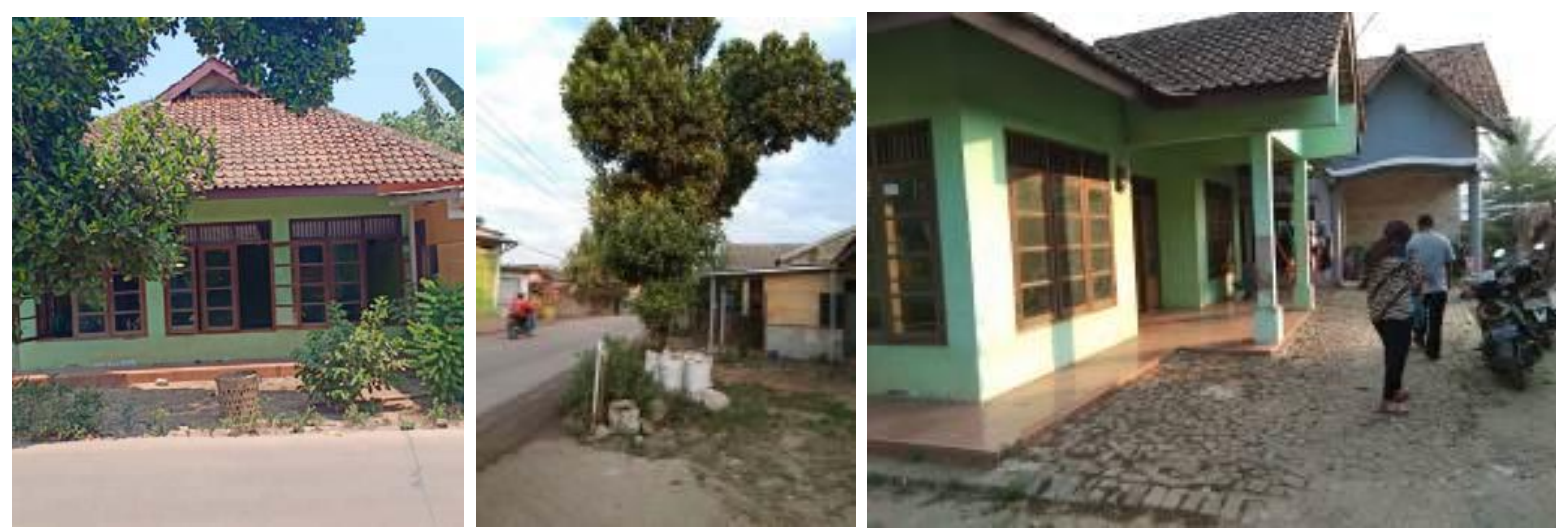

Gambar 3. Kondisi Jalan Raya Dago dan Majelis Taklim Al Musa'adah

Sumber: Dokumentasi, Juli 2019

\subsection{HASIL DESAIN}

Pada bagian pintu masuk (entrance) dibuat krawangan 3D dari panel GRC yang dicat warna coklat kayu (Gambar 4 dan 5). Bentuk krawangan pada bagian entrance dibuat menyerupai kubah masjid. Motif krawangan dibuat heksagonal (segi enam). Di alam semesta bentuk heksagonal biasa ditemui pada sarang lebah. Bentuk heksagonal dipilih karena mempunyai keistimewaan tertentu. Ahli matematika mengemukakan segi enam dipilih lebah karena memiliki bahan untuk pembuatan sarang yang sedikit tetapi dapat mempunyai kapasitas yang besar (http.www.harunyahya.com).

Selain keistimewaan bentuk heksagonal yang sering ditemui pada sarang lebah. Madu yang tersimpan di dalam sarang lebah tersebut juga berfungsi untuk menyembuhkan berbagai macam penyakit. Berdasarkan Al Qur'an, madu sangat dianjurkan untuk menjaga kesehatan dan menyembuhkan manusia dari penyakit (https://ganaislamika.com). Hal tersebut sudah tersirat di dalam ayat Al Qur'an dalam surat An-Nahl ayat 68-69. "Dan Tuhanmu mewahyukan kepada lebah: 'Buatlah sarang-sarang di bukit-bukit, di pohon-pohon kayu, dan di tempat-tempat yang dibikin manusia,' kemudian makanlah dari tiap-tiap (macam) buah-buahan dan tempuhlah jalan Tuhanmu yang telah dimudahkan (bagimu). Dari perut lebah itu ke luar minuman (madu) yang bermacam-macam warnanya, di dalamnya terdapat obat yang menyembuhkan bagi manusia. Sesungguhnya pada yang demikian itu benar-benar terdapat tanda (kebesaran Tuhan) bagi orang-orang yang memikirkan." (Al Qur'an Surat An-Nahl Ayat 68-69). Madu bermanfaat untuk menyembuhkan penyakit berbahaya (jantung dan kanker), gangguan pencernaan, anti bakteri, anti iritasi, anti jamur, meningkatkan stamina, batuk, iritasi tenggorokan, menyembuhkan luka, dan kontrol gula darah (https://dalamislam.com). Warna madu yang berwarna coklat menjadi dasar pertimbangan warna krawangan.

Panel GRC difinishing cat coklat kayu untuk menggambarkan warna madu dan juga memberikan kesan natural. Pada bagian samping entrance juga diberi krawangan 3D untuk memperkuat kesan 3 dimensi dan memberikan pembayangan (shading) agar area entrance lebih teduh.

Shading device pada sisi samping masjid yang berbatasan dengan jalan raya Kabasiran dibuat dari Krawangan 3D dari panel GRC dengan motif sulur daun (Gambar 6 dan 7). Salah satu kaidah arsitektur islam terdapat ketentuan bahwa pada bagian dalam dan luar bangunan tidak boleh ada gambar/ornamen makhluk hidup yang utuh, seperti: hewan atau manusia (https://id.wikipedia.org/wiki/Arsitektur_Islam). Berdasarkan ketentuan tersebut maka sulur daun dipilih sebagai motif krawangan sisi samping bangunan yang juga berfungsi sebagai alat pembayang (shading device). Sulur daun banyak digunakan motif ukiran pada masjid (Gambar 8). 


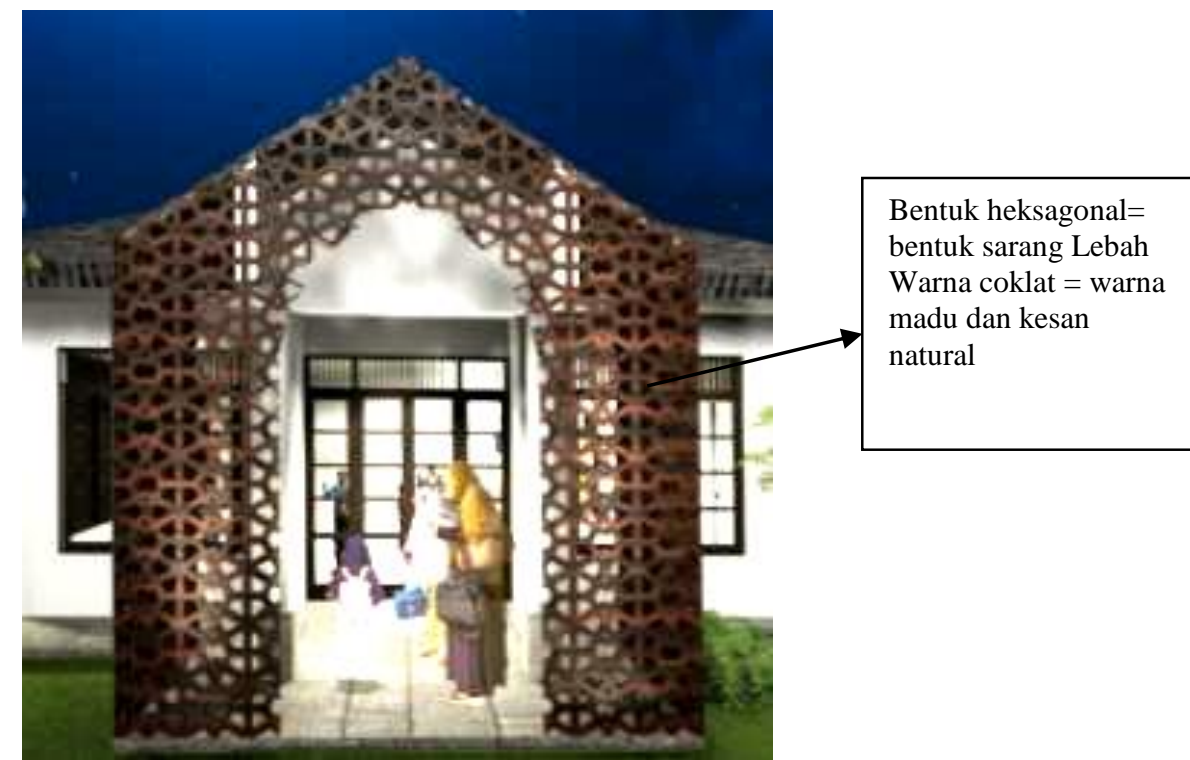

Gambar 4. Rencana Desain Pintu Masuk Majelis Taklim Al Musa'adah Sumber: Penulis, November 2019

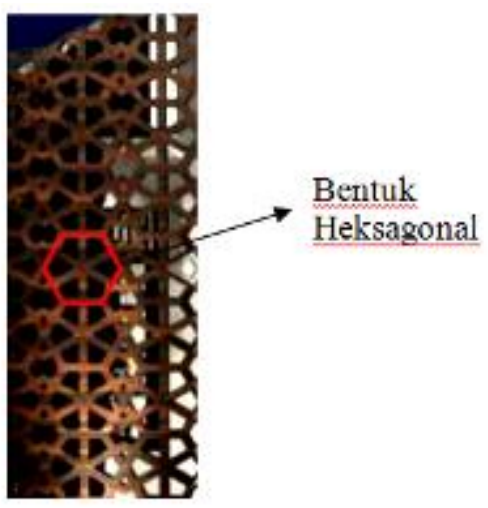

Gambar 5. Bentuk Heksagonal pada Krawangan 3d Entrance Sumber: Penulis, November 2019

Sisi samping majelis mempunyai banyak jendela-jendela besar yang menghadap jalan raya. Oleh karena itu agar tidak terlalu panas maka perlu diberi alat pembayang/peneduh yang bisa diatur kemiringannya. Gambar 7 menunjukkan detail krawangan 3D motif sulur daun yang ditempatkan di sisi samping bangunan. Tinggi krawangan tersebut adalah 3,48 meter dan lebar 0,68 meter. Krawangan 3D sisi samping ini bisa diatur kemiringannya sehingga pada saat cahaya matahari dan angin diinginkan maka krawangan dibuka (diputar dengan sudut $90^{\circ}$ ) begitu pula sebaliknya jika tidak diinginkan dapat ditutup (diatur sejajar dengan dinding samping). Krawangan 3D ini dibuat dengan bahan GRC karena GRC lebih kuat terhadap kelembaban dan cukup kuat untuk diletakkan di outdoor.

Penambahan taman, bangku, dan krawangan 3D tampak terlihat di denah (Gambar 9). Taman ada di bagian depan dan sisi samping kiri bangunan. Bangku ditempatkan di bagian belakang taman. Krawangan 3D ada di bagian depan dan samping bangunan. 


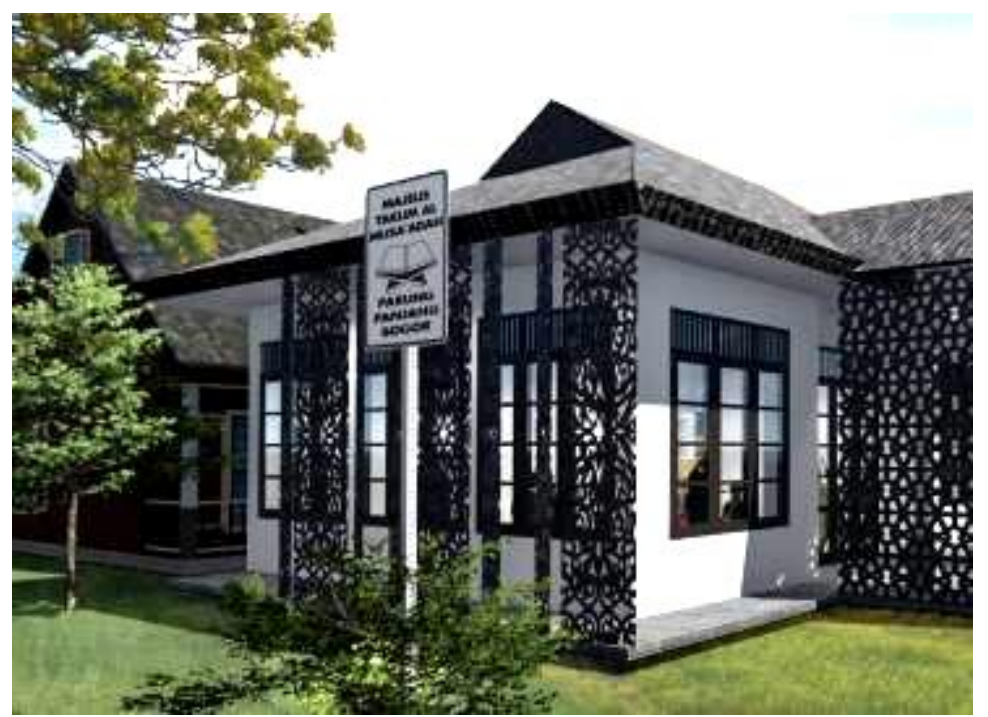

Gambar 6. Rencana Desain Alat Pembayang/Shading Device

Sumber: Penulis, November 2019

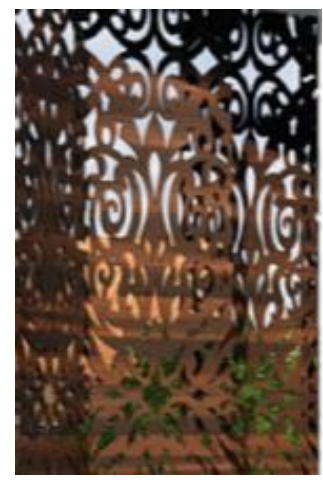

Gambar 7. Motif Sulur Daun pada Krawangan Sisi Samping Majelis

Sumber: Penulis, November 2019

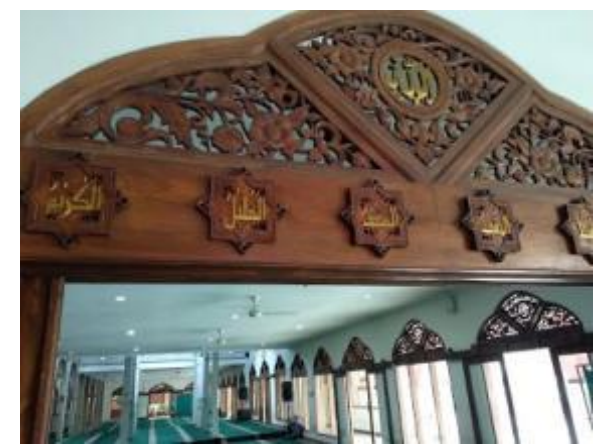

Gambar 8. Motif Ukiran pada Bagian Pintu Masjid Besar Cipaganti, Bandung (Sumber: https://medium.com)

Tampak depan dan tampak samping menunjukkan adanya tambahan krawangan 3D (Gambar 10 dan 11). Motif krawangan 3D pada bagian depan adalah heksagonal sedangkan yang ada di bagian samping adalah sulur daun. Krawangan dibuat dari panel GRC yang difinishing cat coklat kayu. Lantai selasar tetap dipertahankan karena kondisinya masih cukup bagus.

Konsep desain adalah arsitektur Islam. Pintu masuk majelis dibuat seperti bentuk kubah pada bagian lubangnya (Gambar 12). Warna cat dinding diberi warna putih agar terkesan bersih dan 
terang. Warna putih cocok dipadukan dengan warna coklat kayu pada kusen pintu dan jendela. Kusen pintu dan jendela tetap dipertahankan karena kondisinya masih bagus. Plafon yang sebelumnya ditutup anyaman bambu diganti dengan GRC board yang dicat putih sesuai dengan warna bangunan (Gambar 13). Papan lisplang diganti warna putih menyesuaikan warna plafon.

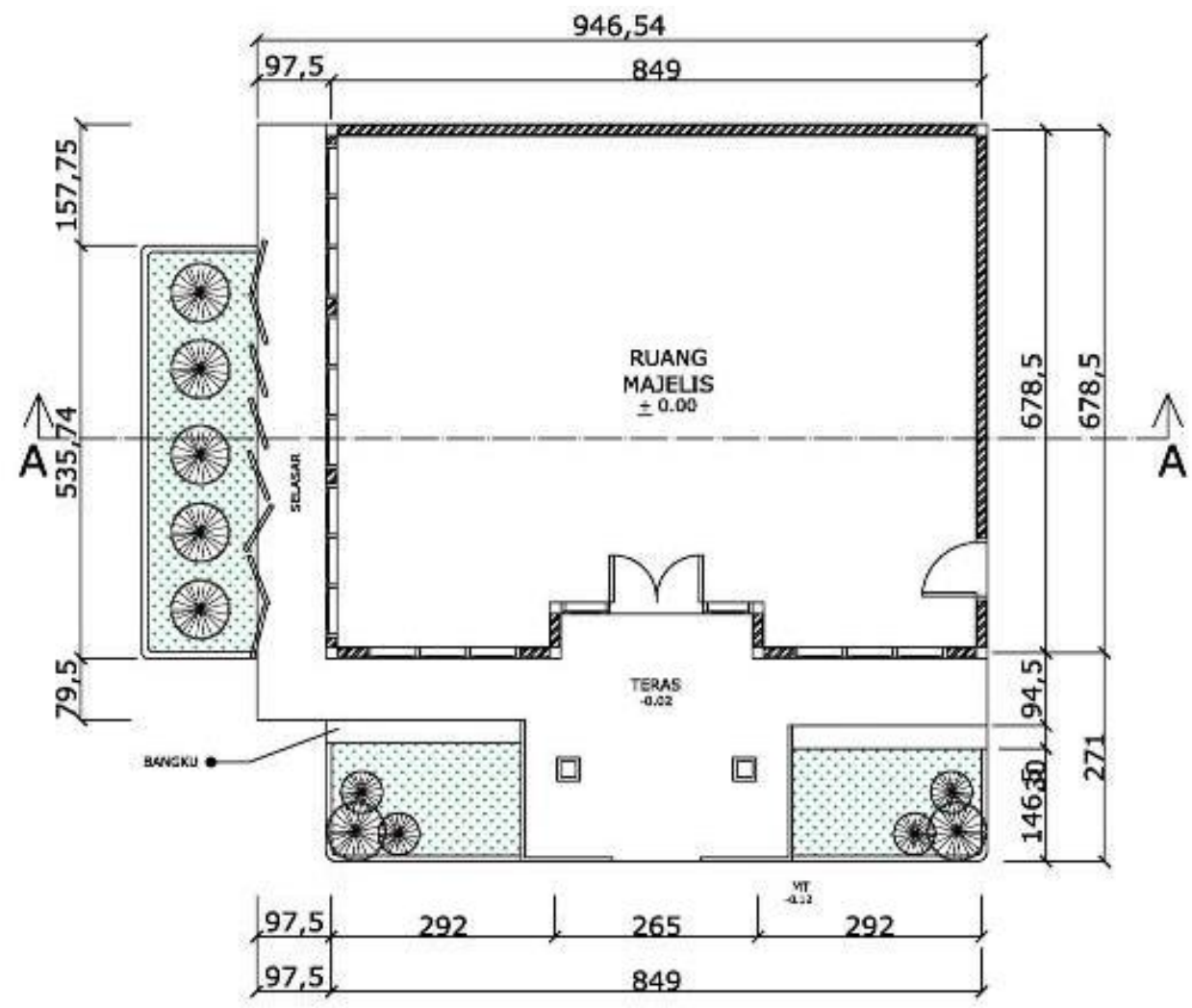

Gambar 9. Desain Denah (Scale to Fit)

Sumber: Penulis, Oktober 2019

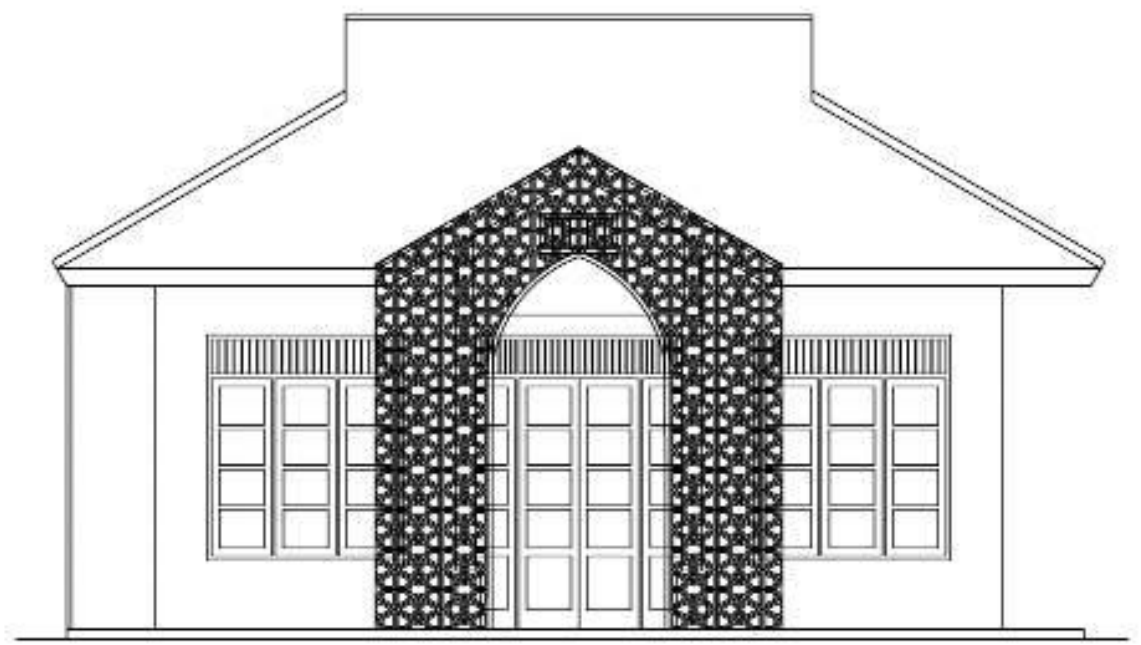

Gambar 10. Desain Tampak Depan (Scale to Fit)

Sumber: Penulis, Oktober 2019 


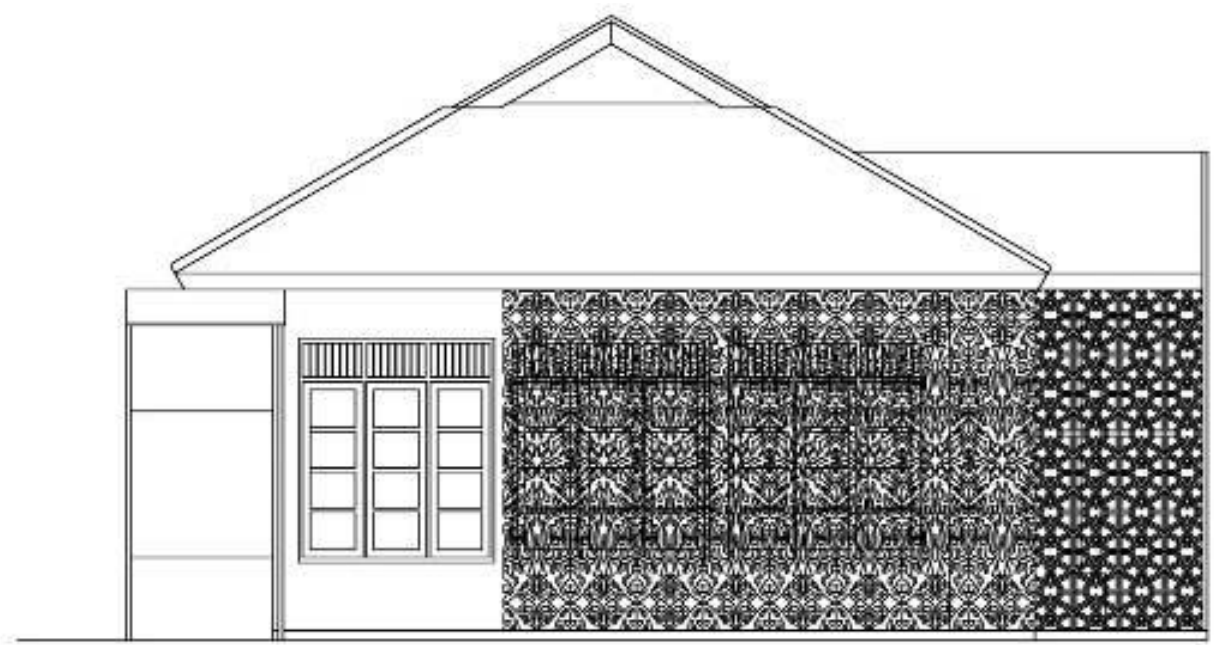

Gambar 11. Desain Tampak Samping Kiri (Scale to Fit) Sumber: Penulis, Oktober 2019

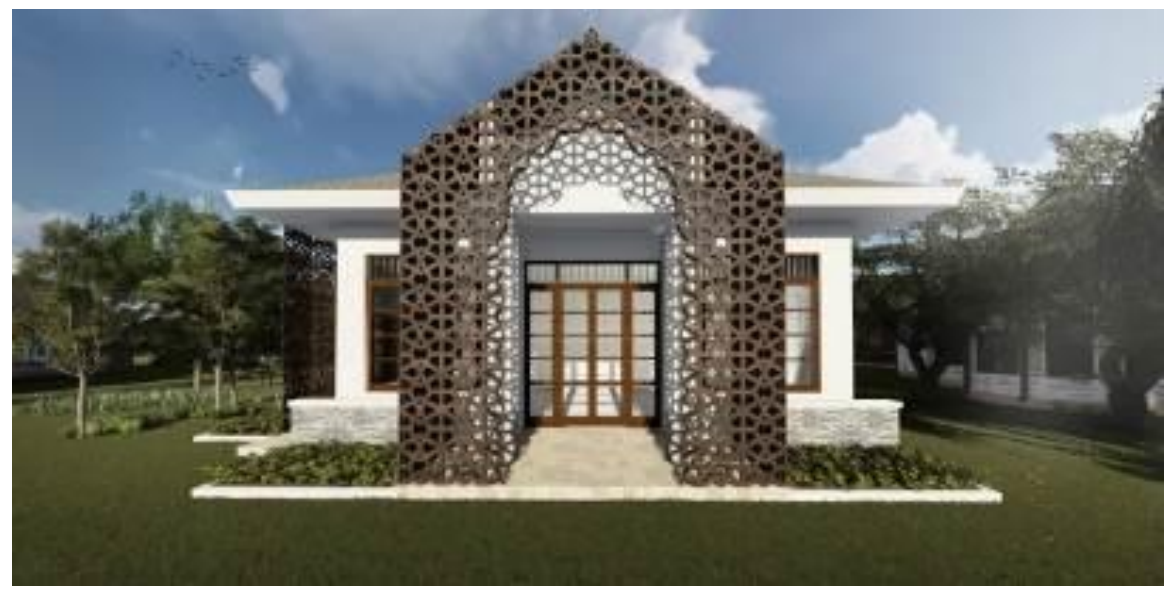

Gambar 12. Perspektif Depan

Sumber: Penulis, November 2019

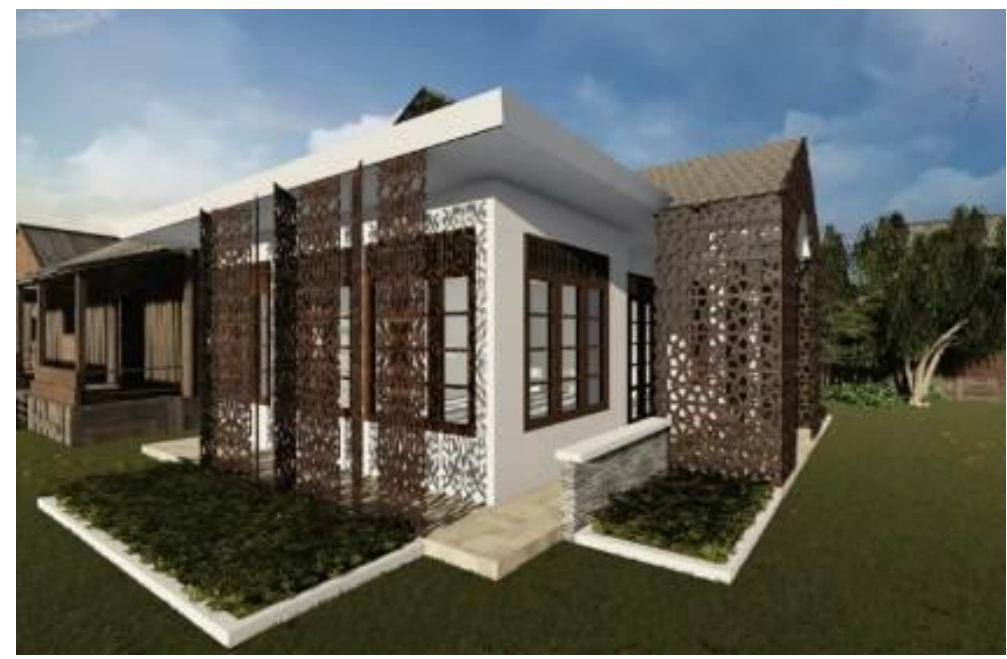

Gambar 13. Perspektif Samping

Sumber: Penulis, November 2019 


\section{KESIMPULAN DAN SARAN}

Re-desain eksterior Majelis Taklim Al Musa'adah perlu dilakukan karena model bangunan majelis hampir menyerupai rumah tinggal. Selain itu tidak adanya papan nama majelis menyebabkan pengguna jalan raya tidak menyadari keberadaan majelis. Oleh karena itu tujuan kegiatan PKM ini adalah mendesain ulang eksterior Majelis Taklim Al Musa'adah berdasarkan arsitektur islam. Lubang krawangan di daerah entrance dibuat model kubah dan pola krawangan dibuat heksagonal. Heksagonal dipilih karena bentuk tersebut mempunyai banyak keistimewaan. Di dalam islam, lebah dan madu tersirat di dalam Al-Qur'an (surat An-Nahl, ayat 68-69). Selain itu motif sulur daun digunakan untuk krawangan 3D sisi samping bangunan karena ornamen di dalam arsitektur islam tidak boleh menggambarkan makhluk hidup, seperti: hewan dan manusia. Penempatan bangku di bagian depan bangunan dan taman di sepanjang selasar dapat membuat peserta majelis menjadi lebih nyaman karena tanaman dapat membuat suasana menjadi lebih dingin dan asri.

Desain eksterior Majelis Taklim Al Musa' yang telah dihasilkan dapat menjadi acuan untuk kegiatan PKM berikutnya. Kegiatan berikutnya adalah melakukan pembangunan eksterior majelis berdasarkan hasil desain kegiatan PKM ini. Kegiatan pembangunan tentu saja memakan baiaya yang cukup besar. Oleh karena itu peran serta masyarakat sekitar sangat diperlukan dalam kegiatan pembangunan. Sumbangan dana dari masyarakat sekitar Majelis Taklim Al Musa'adah diharapkan dapat membantu terwujudnya kegiatan pembangunan.

\section{Ucapan Terima Kasih}

Pada kesempatan ini penulis mengucapkan terima kasih kepada Lembaga Penelitian dan Pengabdian kepada Masyarakat Universitas Tarumanagara, pengurus majelis taklim Al Musa'adah, Bapak Patudin selaku ketua RT.04 Desa Kabasiran sehingga terlaksana kegiatan desain eksterior Majelis Taklim Al Musa'adah.

\section{REFERENSI}

Fikriarini, A. (2010). Arsitektur Islam: Seni Ruang dalam Peradaban Islam. Jurnal El-Harakah, 12 (3), 194-206.

Irawan, R.F, Sumaryoto, Muqoffa, M. (2019). Penerapan Arsitektur Islam pada Perancangan Islamic Center Kabupaten Brebes. Jurnal Senthong, 2(1), 301-310.

Jadidah,A.(2016). Paradigma Pendidikan Alternatif: Majelis Taklim sebagai Wadah Pendidikan Masyarakat. Jurnal Pusaka, 7, 27-42.

Mujahidin. (2018). Urgensi Majelis Taklim sebagai Lembaga Dakwah di Masyarakat. Jurnal Alhadharah, 17(33), 1-12.

Mustofa, M.A. (2016). Majelis Ta'lim sebagai Alternatif Pusat Pendidikan Islam. Jurnal Fokus: Jurnal Kajian Keislaman dan Kemasyarakatan, 1(01), 1-18. 